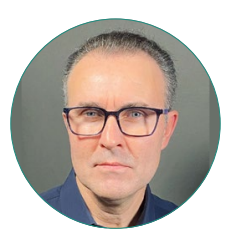

\title{
А. П. Климович \\ РИСКИ КОНЦЕНТРАЦИИ ВЛАСТИ В ЭПОХУ ИСКУССТВЕННОГО ИНТЕЛЛЕКТА: МЕЖДУ СЛЕДЯЩИМ КАПИТАЛИЗМОМ И ЦИФРОВЫМ ЛЕВИАФАНОМ
}

\section{Правильная ссылка на статью:}

Климович А. П. Риски концентрации власти в эпоху искусственного интеллекта: между следящим капитализмом и цифровым Левиафаном // Мониторинг общественного мнения: экономические и социальные перемены. 2021. № 1. С. 154-170. https://doi.org/10.14515/ monitoring.2021.1.1784.

\section{For citation:}

Klimovich A. P. (2021) Risky Concentration of Power in the Age of Al: Between Surveillance Capitalism and Digital Leviathan. Monitoring of Public Opinion: Economic and Social Changes. No. 1. P. 154-170. https://doi.org/10.14515/monitoring.2021.1.1784. (In Russ.) 
РИСКИ КОНЦЕНТРАЦИИ ВЛАСТИ В ЭПОХУ ИСКУССТВЕННОГО ИНТЕЛЛЕКТА: МЕЖДУ СЛЕДЯЩИМ КАПИТАЛИЗМОМ И ЦИФРОВЫМ ЛЕВИАФАНОМ

Климович Александр Павлович кандидат философских наук, научный руководитель Лаборатории по изучению больших данных, Финансовый университет при Правительстве Российской Федерации (Липецкий филиал), Липецк, Россия

E-MAIL: allexgut@gmail.com

https://orcid.org/0000-0002-8912-7635

Аннотация. В статье рассмотрен феномен роста влияния лидеров IT-индустрии, предпринята попытка анализа этого явления. Описаны технологические особенности платформенной архитектуры, способствующие концентрации власти в руках крупнейших концернов информационного рынка. Обрисована бизнес-модель большой пятерки GAFAM, истолкованная в качестве ключевого источника власти цифровых гигантов. Представлено описание качественного отличия цифрового капитализма начала XXI века от индустриального капитализма прошедшего столетия. Изложены подходы критики цифрового капитализма, опирающиеся на опыт критических теорий классиков социологии. Рассмотрены принципы выстраивания отношений государственных структур с ІТ-индустрией с точки зрения баланса и концентрации власти, освещены авторитарные и демократические варианты взаимодействия.

Ключевые слова: GAFAM, цифровой капитализм, платформенный капитализм, следящий капитализм, новые информационные технологии, большие
RISKY CONCENTRATION OF POWER IN THE AGE OF AI: BETWEEN SURVEILLANCE CAPITALISM AND DIGITAL LEVIATHAN

Alexander P. KLIMOVICH ${ }^{1}$ - Cand. Sci. (Soc.), Scientific Adviser at the Big Data Lab

E-MAIL: allexgut@gmail.com

https://orcid.org/0000-0002-8912-7635

${ }^{1}$ Financial University under the Government of the
Russian Federation (Lipetsk Branch), Lipetsk, Russia

Abstract. The paper is focused on a remarkable growth of the IT industry giants' influence. The study describes specific features of platform architecture allowing the largest information market companies to increase their market power concentration. The Big Five (GAFAM) business model is interpreted in terms of the key source of the giants' power. The author describes qualitative differences between the capitalism in the early 21 st century and the 20th-century industrial capitalism. The author outlines approaches to digital capitalism criticism resting on the critical theories of the sociological classics. The author considers rules of the government - IT-industry relationship in terms of balance and concentration of power and touches upon authoritarian and democratic interaction patterns.

Keywords: GAFAM, digital capitalism, platform capitalism, surveillance capitalism, information technology, artificial intelligence, Big data, critical theories, 
данные, критические теории, Франкфуртская школа, демократия, авторитаризм, социальный кредит the Frankfurt school, democracyauthoritarianism, social credit

Цифровые технологии стремительно набирают вес в экономике, государственном управлении, образовании, медицине, медийном пространстве, социальной и приватной жизни каждого человека. Одновременно растет их влияние на современное общество. Особенно четко этот рост прослеживается в сфере экономики, там, где количественные показатели капитализации непосредственно отражают долю влияния компаний на рынке. В статье приведены некоторые статистические данные, отражающие этот процесс. Ниже будет показано, что на сегодняшний день следует говорить не только о количественных изменениях, проходящих под влиянием IT-технологий, но и о возникновении глубоких, качественных перемен в обществе. Будет объяснена целесообразность введения в практику термина "эпоха цифрового капитализма" и описано отличие наступающей эры от эпохи индустриального капитализма. Основная проблема, с которой работал автор, заключается в поиске подходов к анализу рисков концентрации власти при формировании цифрового капитализма. В статье предпринята попытка привлечь к этому анализу критику капиталистических отношений, проделанную рядом социологов на протяжении XX века. Вторая проблема, рассмотренная автором, состоит в анализе взаимодействия государственного управления с лидерами информационного монополизированного сектора.

\section{Принцип генерирования добавленной стоимости при цифровом капитализме}

Для демонстрации степени воздействия цифровых технологий на повседневную жизнь современного человека приведем свежую статистику. Наиболее показательными выглядят данные в области интернет-поиска, социальных сетей и электронной коммерции. Обратим внимание, насколько распространился в мире интернет. Количество активных пользователей в 2020 г. составило 4,54 млрд человек, что приблизительно составляет $56 \%$ жителей планеты. Таким образом, на сегодняшний день каждые шесть из десяти человек активно пользуются всемирной паутиной. На долю поисковой системы Google приходится $76 \%$ всех поисковых запросов в мире. Каждую секунду самая популярная поисковая система отвечает на более чем 40 тыс. поисковых запросов. Продукты и услуги Google насчитывают более 1 млрд пользователей по всему миру, и их число продолжает расти. У сайтов Google самая большая клиентская база с более чем четвертьмиллиардной пользовательской аудиторией. В качестве ведущего домена Google насчитывает 74 млрд посещений в месяц, за ним следует приобретенная в 2006 г. кампанией Google платформа YouTube c 27 млрд посещений ${ }^{1}$.

Список активных пользователей социальных сетей в мире достиг 3,8 млрд человек. В среднем люди проводят в социальных сетях более двух часов в день.

\footnotetext{
1 Основная статистика и факты поиска Google (2020 г.) // Techblog. 2020. 15 октября. URL: https://techblog.sdstudio. top/osnovnaja-statistika-i-fakty-poiska-google-2020-g/\#1_Kazduu_sekundu_v_Google_vypolnaetsa_40_000_zaprosov (дата обращения: 17.02.2021).
} 
Facebook c 2,5 млрд активных пользователей в месяц доминирует среди социальных сетей, каждую минуту в нем регистрируются 400 новых пользователей ${ }^{2}$. Приобретенная в 2010 г. компанией Facebook социальная сеть Instagram имеет более миллиарда активных пользователей в месяц. У Instagram в 58 раз больше активности на одного подписчика, чем у Facebook. B совокупности "инстаграмеры" "лайкают" в день более четырех миллиардов сообщений ${ }^{3}$.

Вместе с распространением интернета стремительно растет рынок электронной коммерции. Общий объем продаж на этом рынке в 2019 г. составил 4,2 трлн долл. В 2022 г. это число превысит 6,54 трлн долл. По данным Statista, доля розничных продаж в электронной коммерции составляет около $15 \%$, и с каждым годом растет ${ }^{4}$. По результатам 2020 г. более половины онлайн-продаж в мире приходится на Amazon. Только лишь в Америке компания ежедневно осуществляет более 3 млн заказов ${ }^{5}$.

Взглянув на список публичных финансовых предприятий с наибольшей рыночной капитализацией, мы обнаружим, что на второй квартал 2020 г. его возглавляли пять крупнейших IT-компаний: Alphabet (Google), Apple, Facebook, Amazon, Microsoft. Так называемая большая пятерка GAFAM с 2016 г. регулярно занимает первые позиции в рейтинге самых ценных компаний мира ${ }^{6}$. За последние два года четырем из пяти гигантов удалось преодолеть порог капитализации в 1 трлн долларов ${ }^{7}$. Совокупная стоимость этих пяти компаний превысила 5,3 трлн долл., ${ }^{8}$ что составило более $40 \%$ суммарной стоимости акций всех компаний, торгующихся на американской бирже Nasdaq ${ }^{9}$. Анализируя динамику развития техногигантов, трудно не обратить внимание на беспрецедентный рост объемов и скорости их рыночной стоимости. Пятерка лидеров ІТ-индустрии за последние несколько лет продемонстрировала невиданный в истории экономический рывок, побив все рекорды концентрации капитала.

Глобальные трансформации, вызванные цифровыми технологиями, порождают дебаты о необходимости разработки новых институтов и правил регулирования экономики и общества [Lobel, 2016]. Феномен роста крупнейших игроков цифровой индустрии воспринимается рядом аналитиков как индикатор качественного изменения мировой политэкономической системы и в академической среде отражается введением в дискуссию таких терминов, как "цифровой капитализм" [Staab, 2019], "платформенный капитализм" [Srnicek, 2016; Langley, Leyshon,

\footnotetext{
2 Общая статистика Facebook. URL: https://www.websitehostingrating.com/ru/facebook-statistics/\#chapter-1 (дата обращения: 17.02.2021).

340 + Instagram Статистика и факты для 2020. URL: https://www.websitehostingrating.com/ru/instagram-statistics/ (дата обращения: 17.02.2021).

4 Статистика Интернета 2020: сайты, домены, хостинг, трафик. URL: https://sdvv.ru/articles/elektronnaya-kommertsiya/ statistika-interneta-2020-sayty-domeny-khosting-trafik/ (дата обращения: 17.02.2021).

5 Статистика Amazon. URL: https://amzmln.com/stati/amazon/statistika-amazon/ (дата обращения: 17.02.2021).

6 Ovide Sh., Molla R. Technology Conquers Stock Market. 2016. August 2. URL: https://www.bloomberg.com/opinion/ articles/2016-08-02/tech-giants-form-fab-five-to-dominate-stock-valuation-chart (дата обращения: 17.02.2021).

7 List of Public Corporations by Market Capitalization //Wikipedia. URL: https://en.wikipedia.org/wiki/List_of_public_ corporations_by_market_capitalization\#2000 (дата обращения: 17.02.2021).

8 Größte Unternehmen der Welt nach ihrem Marktwert im Jahr 2020 //Statista. URL: https://de.statista.com/statistik/ daten/studie/12108/umfrage/top-unternehmen-der-welt-nach-marktwert/ (дата обращения: 17.02.2021).

9 NASDAQ 100 //Insider. https://markets.businessinsider.com/index/nasdaq_100 (дата обращения: 17.02.2021).
} 
2016] или "следящий капитализм" [Zuboff, 2018]. Каждый термин отражает специфику исследовательского подхода. Цифровой капитализм рассматривает экономическую логику бездефицитных рынков, платформенный капитализм делает ставку на рассмотрение технологической основы, следящий капитализм концентрируется на аспекте сбора поведенческих данных.

С технологической точки зрения IT-гиганты - это цифровые платформы, предлагающие услуги на информационном рынке. Платформа представляет собой "киберпространство", формируемое при помощи алгоритмов, в которых пользователи совершают операции, взаимодействуют и заключают сделки [Zysman, Kenney, 2016: 11]. Операции могут быть классифицированы как экономические, социальные или технические действия участников. С другой стороны, под платформами понимаются управляемые компьютером, программируемые и алгоритмически структурированные технологические архитектуры, на которых может быть основано множество конкретных приложений и которые сегодня образуют центральную техническую инфраструктуру сети [Gillespie 2010: 350].

Платформы условно можно разделить на несколько основных типов. Прежде всего, это поисковые платформы. Другой тип-сети и платформы для обмена сообщениями, например Facebook, WhatsApp, Instagram, Twitter или Snapchat. Kроме того, важную роль играют медиаплатформы, такие как YouTube, Netflix или Spotify. Особое место занимают торговые платформы, среди которых Amazon, Alibaba, eBay или Zalando. Стоит также обозначить посреднические платформы, например, в сфере услуг вождения (Uber, Lyft), бронирования путешествий и гостиничных номеров (Airbnb Expedia, booking.com) или знакомств (Match, Parship) [Dolata, 2019].

Существует множество платформ, и не все из них техногиганты. Некоторые еще находятся в положении независимых стартапов, другие уже поглощены более крупными и стали частью холдинга одного из монополистов (как YouTube и WhatsApp). Приведенные выше статистические данные иллюстрируют тенденцию современной цифровой индустрии к монополизации. Этому факту есть вполне конкретные объяснения. Ключевая особенность развития современных технологий заключается в принципе "победитель получает все", опирающемся на пять специфических для платформенной архитектуры факторов [Moore, Tambini, 2018: 33].

1. Программное обеспечение, формирующее платформы, имеет высокие фиксированные затраты на разработку, но минимальные расходы на копирование и распространение цифрового контента. То есть удельные затраты на создание платформ обратно пропорциональны объему продаж. Это дает значительное конкурентное преимущество политике максимально быстрого и широкого распространения продукта на рынке (фактор масштабирования).

2. Платформы вбирают в себя свойства сетевых структур, полезность которых прямо пропорциональна количеству подключенных к сети участников [Jeffrey, 1974: 16]. В более выигрышном положении оказывается сеть, успевшая включить в себя наибольшее количество абонентов (сетевой фактор).

3. На платформах, осуществляющих связь продавцов с покупателями, возникает симметрия между предложением и спросом. Количество участников одной части рынка (например, отелей) зависит от количества участников другой части рынка (путешественников, бронирующих номера) (фактор симметрии). 
4. Эффект, связанный со сложностью переключения с одной платформы на другую, где требуется дополнительное усилие пользователя по освоению нового интерфейса. Чем больше объем такого обучения, тем выше стоимость переключения.

5. Платформы, обладая практически неограниченными возможностями транспортировки данных, могут осуществлять их повсеместный сбор и использовать для обучения искусственного интеллекта. Получая доступ к большим данным, лидеры рынка становятся обладателями информации для тактического и стратегического улучшения качества продукта, что позволяет им выигрывать конкуренцию у игроков, не имеющих этого доступа (фактор больших данных).

Все эти эффекты действуют в одном направлении, повышая шансы победителя и закрепляя его положение лидера, способствуют образованию доминантных игроков и монополизации рынков. Однако последний (пятый) эффект имеет особое значение. Он основан на применении технологии машинного обучения искусственного интеллекта. Широкомасштабное применение этой технологии проводит черту между периодом "оцифрованного капитализма", элементы которого проявились в 1960-е годы (после первых попыток автоматизации процессов производства), и эрой современного "цифрового капитализма", в которой поведенческие данные используются в качестве основы генерирования добавленной стоимости, а сбор этих данных положен в основу бизнес-моделей техногигантов, занявших ключевые позиции влияния на рынке цифровых технологий [Staab, 2019: 38].

Бизнес-модели крупнейших акторов цифровой индустрии различны. Не все они основаны на продаже онлайн-рекламы, однако у всех есть общее свойство - они собирают данные пользователей и используют машинное обучение искусственного интеллекта для их обработки в целях дальнейшей оптимизации своего продукта. Американская экономистка Шошана Зубофф провела подробный критический разбор бизнес-моделей техногигантов GAFAM, в котором показала, что в основу создания добавленной стоимости всех этих корпораций положен сбор пользовательских поведенческих данных [Zuboff, 2018]. Анализ действий ключевых игроков цифрового рынка показывает, что сбор и обработка больших данных первостепенная задача всех крупнейших акторов IT-индустрии. Постепенно в круг собирателей данных вовлекаются все больше отраслей и участников. Интернет вещей, индивидуальная медицина, автономное вождение - это лишь некоторые примеры способов массового сбора поведенческих данных. В современном мире следящего капитализма большие данные стало принято называть "новой нефтью" по аналогии с тем, что именно нефть была основой строительства крупного капитала прошлого столетия.

Появление фордизма и тейлоризма стало началом применения новой экономической логики, сформировавшей капитализм массового производства XX столетия. Подобным образом на рубеже XXI века в Кремниевой долине была открыта экономическая логика, потеснившая классический принцип массового производства с вершины олимпа прибыльности. Построенная на производстве продукта, основанного на сборе данных, эта логика стала фундаментом бизнесмодели капитализма XXI века [Климович, 2020а].

Логично, что вопрос концентрации капитала в конечном счете должен сводиться к вопросу о концентрации власти. В современных условиях, когда технологии 
усиливают тенденции к монополизации, проблема распределения и баланса власти приобретает новый масштаб. В такой ситуации перед социологами стоит задача проведения всестороннего анализа цифрового капитализма, а вместе с тем и пересмотра роли и значения технологий в обществе.

\section{Подходы к критическому анализу цифрового капитализма}

Несмотря на то что цифровой капитализм использует качественно новую логику создания добавленной стоимости, отличающую его от классического капитализма, все же он не перестает быть капитализмом - формацией, основанной на частной собственности и свободном рыночном предпринимательстве, направленном на повышение прибыли и увеличение капитала. Поэтому, делая попытку осмысления социальных эффектов цифрового капитализма, логично обратиться к опыту критики индустриального общества, проделанной классиками социологии, авторами критических теорий XX столетия.

Ключевым свойством платформенной архитектуры оказывается сбор и обработка информации. Именно сбор больших данных обеспечивает IT-лидерам конкурентное преимущество, позволяет удерживать доминантное положение и распространять экономическое политическое и общественное влияние. Возможность сбора и анализа поведенческих данных приводит к открытию нового источника знаний - новой силы, способной стать локомотивом развития. По мере того, как поведение людей превращается в информацию, распределение прогностического знания в обществе становится доминирующим принципом социального порядка. Знание, извлекаемое из поведенческих данных, генерируемых в экспоненциально возрастающем объеме, распределяется неравномерно. Это явление усугубляется по мере накопления данных на серверах ІТ-гигантов, которые отнюдь не заинтересованы делиться ими с остальным миром.

Проблема дифференциации доступа к экономическим, социальным, политическим и культурным ресурсам была рассмотрена основателем французской социологии Эмилем Дюркгеймом более ста лет назад. По мнению французского социолога, разделение труда легло в основу установления разного рода взаимозависимостей, которые, объединив членов социума в более широком контексте солидарности, способствовали установлению социального и морального порядка современного индустриального общества [Дюркгейм, 1991]. Однако ученый отметил, что чрезмерная социальная дифференциация, вызванная неравноправным распределением ресурсов, становится источником патологий, в результате которых возникает так называемое аномическое разделение, вызывающее социальную дистанцию, несправедливость и конфликты вместо установления взаимодействия и взаимозависимости, формирующих общественную солидарность.

В цифровом обществе, когда право распределения прогностическим знанием все отчетливее проявляет себя как форма власти, неравномерность распределения этого знания угрожает последствиями, о которых предостерегал Дюркгейм. Наблюдение, осуществляемое платформами посредством сбора и обработки персонализированных данных, обеспечивает IT-корпорациям конкурентное преимущество и создает прогрессирующую асимметрию знаний, повышает риски возникновения эффектов, описанных французским социологом. 
В контексте анализа последствий неравномерности распределения доступа к новому типу знания имеет смысл вспомнить о классическом "эффекте Матфея". Этот термин, предложил американский социолог Роберт Мертон для описания феномена прогрессирующего неравенства, состоящего в том, что сторона, уже обладающая преимуществами, продолжает их накапливать, в то время как другая, изначально ограниченная, оказывается обделена еще сильнее [Мертон, 1993]. Как было показано выше, этот эффект отчетливо проявляется в платформенной архитектуре.

Отдельно отметим, что проблема цифрового неравенства, обсуждаемая в контексте неравномерного доступа к интернету [Быков, Халл, 2011], скорее всего, не является специфической проблемой цифрового капитализма. Более того, логика цифрового капитализма как раз состоит в том, чтобы обеспечить максимально широкий охват сбора поведенческих данных, и для реализации этой цели инвесторы, зарабатывающие на продаже предиктивной информации, по всей видимости, не будут жалеть средств на развитие инфраструктуры сбора транспортировки и обработки данных, что в принципе подтверждается статистикой о динамике распространения интернета по всему миру ${ }^{10}$.

Продолжая сопоставление критики индустриального общества с контекстом цифрового капитализма, нельзя не обратиться к опыту критических теорий, предметом которых является анализ буржуазно-капиталистических отношений, направленный на раскрытие механизмов господства и подавления. Основатели Франкфуртской школы Теодор Адорно и Макс Хоркхаймер выяснили, что благодаря чрезмерной фокусировке капиталистического производства на извлечении прибыли и приумножении капитала оптимизация и эффективность в индустриальном обществе были возведены в ранг высшего приоритета.

Рассмотрев эффективность применительно к понятию “самоцель", они выделили тип человеческой деятельности, направленный на повышение эффективности, но игнорирующий вопрос о цели этого повышения. По мнению немецких социологов, этот принцип положен в основу так называемого инструментального разума, который начал доминировать в западной культуре со времен эпохи Просвещения. Примат господства инструментального разума стал питающей почвой, на которой впоследствии пустил корни современный западный капитализм. Развитый модерн характеризуется тем, что общество неизбежно превращается в систему, в которой все элементы соподчинены функциональной зависимостью. Каждая часть воспринимает другую часть в качестве ресурса. То, что не является ресурсом, игнорируется системой и, исключаясь из внимания, низводится до статуса неинтересного, безразличного, исключенного. Напротив, то, что является ресурсом, используется с максимальной эффективностью, вовлекаясь в структуру социальных связей. Логика капиталистического общества полностью отражает стремление человека инструментализировать окружающую среду. В конечном счете этой цели подчиняется вся деятельность общества, включая современную

\footnotetext{
${ }^{10}$ Вся статистика интернета на 2020 год-цифры и тренды в мире и в России. URL: https://www.web-canape.ru/ business/internet-2020-globalnaya-statistika-i-trendy/ (дата обращения: 17.02.2021); Список стран по числу пользователей интернета. URL: https://ru.wikipedia.org/wiki/Список_стран_по_числу_пользователей_Интернета (дата обращения: 17.02.2021).
} 
науку. Говоря словами Т. Адорно и М. Хоркхаймера, единственное, чему люди хотят научиться у природы, это как ее использовать, чтобы полностью поработить [Хоркхаймер, Адорно, 1997: 17].

Перенося критику немецких классиков на цифровой капитализм, можно провести некоторые параллели. В частности, любой IT-предприниматель, как и всякий субъект капиталистических отношений, преследует цель повышения оптимизации производимого продукта. Однако в случае с глобальными платформами, чья бизнес-модель опирается на извлечение прибыли за счет сбора персонализированных данных, происходит нечто особенное. Оптимизация их продукта основана на анализе поведенческой информации и создании нового типа приватизированного прогностического знания, что в итоге делает возможным доминирование IT-концернов во всех областях деятельности - экономике, политике, науке, образовании, медицине. Если в индустриальном обществе в погоне за прибылью инструментализации подвергалась окружающая природа, то в цифровом обществе инструментализации подвергается сам человек. Поставленный на службу производства удобного и “бесплатного" продукта, субъект, предоставляя бесконтрольный доступ к персональным данным, жертвует своим правом свободного, независимого выбора. Механизм этого обмена обществу еще предстоит изучить, но для данной статьи важно подчеркнуть, что у ІТ-гигантов есть все основания скрывать стоящую за сбором персональных данных суть инструментализации человека и вуалировать реальное положение дел подобно тому, как это делали крупные концерны эпохи индустриализации, лоббируя интересы производств и отраслей, наносящих непоправимый вред окружающей среде.

В контексте оценки рисков влияния цифровых технологий на общество следовало бы обратить внимание на критический анализ классического капитализма, проделанный еще одним представителем Франкфуртской школы Гербертом Маркузе. В работе "Одномерный человек" ученый анализирует саму возможность противостояния негативным эффектам, которые возникают в результате распространения технического прогресса и модернизации общества. Изучая происходившие в XX веке изменения, Маркузе приходит к выводу, что в связи с успехами применения научно-рационалистической методологии как в научном, так и в публичном пространстве устанавливается так называемое одномерное мышление, исключающее альтернативные подходы к развитию познания [Marcuse, 1970]. Немецкий классик констатирует, что разнообразие перспектив развития общества схлопывается в одномерность отсутствия альтернативы не путем наложения запрета, а с помощью отключения у индивида самого осознания возможности альтернативы. Любой выход "за рамки" маркируется как нецелесообразный, бесполезный и даже нереалистичный, таким образом превращаясь, по выражению Роберта Мертона, в самоисполняющееся пророчество [Мертон, 2006]. То есть с момента того, как человек принимает безальтернативность, она реализуется как действительный факт. Объясняя причины сформировавшейся в результате технического прогресса безальтернативности, Маркузе различает истинные и ложные потребности человека. Истинные потребности возникают на основе собственных представлений и интересов личности, а ложные имеют природу внешнего воздействия, навязываются ему извне. Именно внешнее воздействие, 
по мнению представителя Франкфуртской школы, ответственно за нормализацию одномерного мышления.

Применяя доводы немецкого социолога к контексту анализа платформенного капитализма, следует обратить внимание на особое значение злоупотребления технологиями сбора поведенческих данных. Простая логика подсказывает, что чем шире возможности манипулирования человеком, тем менее заметен этот процесс для него самого, ровно как верно и обратное. В мире неконтролируемого сбора поведенческих данных с новой силой возрастают риски реализации сценария Маркузе, когда одномерное мышление угрожает отстранением человека от самостоятельного формирования собственного будущего. Платформенная архитектура, обеспечивающая сбор персональных данных, создает благоприятную среду для распространения технологий подталкивания [Талер, Санстейн, 2017]. В сочетании с технологией микротаргетинга, опирающегося на анализ больших данных и воздействующего индивидуально на каждого субъекта в автоматизированном режиме, возрастает риск манипулирования массовым сознанием. Создается угроза отключения альтернативных вариантов развития целого общества путем персонального убеждения каждого пользователя в нецелесообразности или невозможности их реализации. По словам Паула Шварца, чем больше информации известно о человеке, тем легче им управлять. Поэтому, чтобы защитить лежащую в основе демократии свободу, необходимо тщательно продумать, как общество должно обращаться с информацией, каким образом оно будет гарантировать равноправный доступ к ней и как должна обеспечиваться ее надежная защита [Schwartz, 1989].

Продолжая сопоставлять анализ рисков цифрового капитализма с классической критикой индустриального общества, нельзя оставить без внимания, пожалуй, самого известного представителя Франкфуртской школы второго поколения Юргена Хабермаса. По мнению Хабермаса, модернизация предоставляет человеку определенный шанс построения свободного демократического общества, реализовать который можно посредством механизма ограничения власти через публичность [Хабермас, 2016]. Такой принцип контроля подразумевает выяснение истины не в режиме отсылки к авторитету, а через всеобщее и добровольное принуждение лучшего аргумента.

Хабермас - представитель теории дискурса, в его концепции закон и право определяются истиной, а не авторитетом. Публичное пространство состоит из участников, выполняющих роль гражданских репрезентантов, активно защищающих свою позицию.

Таким образом, по мере разворачивания модернизационных процессов именно публичность становится медиумом построения демократии. Дискурс, выступая в качестве процедурного момента установления истины, становится эссенциальным свойством демократического строя. Демократия представляет собой процедурное явление, реализованное посредством широкомасштабного применения дискурсивных практик, в рамках реализации которых Хабермас различает два типа действий. Коммуникативное действие происходит в контексте планов участников коммуникации и направлено на достижение взаимного понимания между ними. Такое действие построено на совместном координировании 
своих намерений в зависимости от прояснения и понимания противоположных позиций. Стратегическое действие направлено на достижение индивидуального успеха. Реализуя стратегическое действие, актор поступает, невзирая на интересы и потребности другого, принимая во внимание лишь возможности, обеспечиваемые доступом к ресурсам. В стратегическом действии акторы стремятся взять свои цели за ориентир и пытаются оказать влияние на решения других акторов [Habermas, 1988: 131].

Такие элементы человеческой реальности, как знания, социальный порядок, общественное пространство, относятся к структурам “жизненного мира" и могут быть репродуцированы исключительно посредством механизма взаимопонимания, на основе коммуникативного действия. В процессе модернизации общества от "жизненного мира", в котором доминирует коммуникативное действие, постепенно отделяется "система", включающая в себя область экономики и административного управления. Системные процессы, репродуцируемые на основе стратегического действия, достигая высокой степени эффективности, имеют тенденцию распространения, и в ряде случаев просматривается тренд вытеснения этими процессами менее эффективных, не приносящих сиюминутный результат коммуникативных действий. Критика Хабермаса показывает, что в ряде случаев этот феномен следует диагностировать как социальную патологию, при этом сам процесс ученый называет колонизацией жизненного мира системой.

Применяя терминологию Хабермаса к анализу цифрового капитализма, следует отметить, что коммуникативное действие, составляющее основу жизненного мира, опирается на право свободного выбора, который участники коммуникации предположительно должны совершить в процессе поиска взаимного понимания. То есть акторы должны находиться в равных категориях доступа к информации о мотивах действия друг друга. В случае применения технологий микротаргетинга и машинного обучения собираемые персональные данные человека используются для формирования предсказаний его поведения. При взаимодействии с платформой пользователь, передавая свои персональные данные, делится информацией о собственных мотивах, однако мотивы действия платформы остаются для него закрытыми и неясными. Чем больше пользовательских данных собирает платформа, тем больше у нее информации о том, как будет действовать пользователь. Напротив, чем более сложной становится платформа, тем меньше пользователь имеет представление о принципах ее функционирования. Взаимодействуя с платформой в режиме ассиметричного доступа к прогностической информации, человек с каждым актом взаимодействия теряет контроль над собственным действием, передавая его инстанции - обладателю этой информации, то есть самой платформе. Такое взаимодействие не может быть отнесено к классу коммуникативного действия, так как участники находятся в разных категориях доступа к информации о мотивах действия друг друга. Однако оно имеет все признаки стратегического действия ввиду того, что основано на доступе к ресурсу - прогностической информации. Повсеместное распространение действия платформ в современном мире, скорее всего, следует интерпретировать как процесс колонизации жизненного мира системой, при котором логика эффективности вытесняет логику понимания и при необходимости может оправдывать применение механизмов манипулиро- 
вания [Климович, 2019]. Этот вывод вызывает особое беспокойство в контексте анализа рисков концентрации власти цифрового капитализма.

\section{IT и государство}

Анализируя проблему монополизации власти, необходимо рассмотреть тему взаимодействия IT-индустрии с государственными структурами. Характер их взаимодействия зависит от того, с каким типом государства мы имеем дело - демократическим или авторитарным. Несмотря на то что наблюдаются некоторые общие процессы, характерные для обеих ситуаций, все же различия достаточно велики, так что проанализируем оба варианта по отдельности. Вариант демократического государства хорошо иллюстрирует пример США, а случай взаимодействия IT-технологий с авторитарным типом государства - пример Китая.

Рассматривая ситуацию в Соединенных Штатах, начнем с того, что на практике часто наблюдается тесное взаимодействие техногигантов с государственными структурами. Достаточно посмотреть на совместные проекты в области образования, медицины, автоматизации муниципального и государственного управления. Особенного внимания заслуживает сотрудничество с военными разведывательными и правоохранительными органами [Черняк, 2013] которое объясняется не только стремлением крупных финансовых институтов путем сближения с властными структурами влиять на регулирование цифровой отраслью. Степень и характер взаимодействия убедительно демонстрируют, что сами государственные институты заинтересованы в сотрудничестве с IT-корпорациями. В каком-то смысле заинтересованность государственных органов очевидна, ведь IT-технологии значительно повышают эффективность менеджмента. Какую бы область мы ни брали в качестве примера - медицину, образование, безопасность,везде применение цифровых технологий приводит к значительному повышению эффективности управления.

Возвращаясь к вопросу концентрации власти цифровых технологий, при более внимательном анализе можно обнаружить, что государственным структурам в определенном смысле выгодно положение монополизированного рынка IT. Государственный контроль, имеющий целью управление, и сбор поведенческих данных частными компаниями для доминирования на рынках тесно связаны между собой. Монополизм цифровых платформ выступает ключом к успеху государственного менеджмента. Сотрудничающий с властями глобализированный технологический сектор - гораздо более удобный союзник в проекте государственного контроля, чем фрагментированный, состоящий из мелких независимых субъектов.

Особенно высокая степень взаимодействия обнаруживается в области сотрудничества с государственными системами безопасности. В связи с развитием монополизированного IT-сектора службы безопасности получили возможность сократить значительную часть расходов по сбору информации, что сделало их работу несоизмеримо более эффективной. Благодаря цифровым платформам теперь устройства самих граждан собирают бо́льшую часть данных, которые государственные службы используют для наблюдения за ними [Zuboff 2018: 431]. Граждане сами оплачивают эти устройства, а также услуги, к которым подключены, и сами кропотливо вводят данные, связанные с регистрацией фактов об их жизни, 
мнениях и предпочтениях. Склонность к симбиозу государственных структур и цифровых платформ объясняется тем, что Big Tech, собирая данные, может легко это делать для служб безопасности, а агентства безопасности - следить за тем, чтобы правительства не ограничивали деятельность Big Tech. Исполнительным органам удобно прибегнуть к возложению дорогостоящих государственных обязанностей на крупные технологические компании, например автоматическое выявление нарушения авторских прав, обнаружение террористического и экстремистского контента. Дилемма состоит в том, что можно пытаться сократить власть цифровых гигантов, лишив их монопольного права владения рынками, либо возлагать на них контроль над выявлением нежелательных действий пользователей, но проблематично сделать и то и другое одновременно ${ }^{11}$.

Анализ взаимодействия технологического сектора со структурами демократического государства показывает амбивалентный характер этих отношений, проявляющийся в том, что, с одной стороны, демократическое государство стоит на защите индивидуальной свободы и прав человека, с другой стороны, заинтересовано в эффективном управлении и обеспечении безопасности граждан. Говоря о демократическом государстве, мы прежде всего подразумеваем наличие в нем разделения независимых ветвей власти: исполнительной, законодательной и судебной. Наличие этих институтов эссенциально для демократического строя. Применительно к нашему анализу концентрации власти в эпоху цифрового капитализма следует отметить, что исполнительная ветвь более склонна к "коллаборационизму" с монополизированным технологическим сектором. Для восстановления баланса властных полномочий следует учитывать этот эффект и делать опору прежде всего на гражданское общество, судебную и законодательную ветви власти.

Рассматривая китайский сектор рынка информационных технологий, следует отметить, что, хоть он и отделен от остального интернета великой огненной стеной, все же эффекты монополизации проявлены здесь не меньше, чем на мировом рынке. Аналогом американского GAFAM здесь выступает тройка крупнейших игроков: Tencent, Alibaba, Baidu, в которой сконцентрирован основной ресурс китайской IT-индустрии. В отличие от демократических стран, частные компании Китая находятся в совершенно других отношениях с государством. Имея относительную свободу в области разработки продукта, китайские техногиганты находятся под полной зависимостью от политической воли коммунистической партии. Правительство народной республики непосредственно определяет стратегию развития страны, в том числе глобальные планы по внедрению IT-технологий в общественную жизнь. Осознавая, что использование технологий искусственного интеллекта открывает возможность централизованного и эффективного управления огромной страной, правительство народной республики рассчитывает, что в перспективе суперкомпьютерам будет передана роль создателей генерального плана развития экономики.

Говоря о роли, которую цифровые технологии играют в формировании общественной жизни Китая, имеет смысл обратиться к примеру создания системы

\footnotetext{
${ }^{11}$ Doctorow C. How to Destroy Surveillance Capitalism // OneZero. 2020. August 26. URL: https://onezero.medium.com/ how-to-destroy-surveillance-capitalism-8135e6744d59 (дата обращения: 17.02.2021).
} 
социального кредита. [Климович, 2020b]. Цель системы состоит в том, чтобы осуществлять всесторонний контроль за людьми посредством сбора и обработки их персональных данных. В рамках реализации системы предполагается анализ общественно-политического поведения частных лиц, компаний и других организаций для определения их "социальной репутации", на основе которой будет проводиться поощрительная и санкционная политика регулирования ${ }^{12}$. В этом проекте государство активно задействует ресурсы частных компаний, привлекая весь арсенал влияния. Данные о гражданах, собираемые IT-компаниями, по указанию правительства используют в расчетах оценки социального кредита ${ }^{13}$. Крупнейший оператор поисковых систем Китая Baidu указан как один из центральных разработчиков платформы. Также в разработку системы рейтинга вовлечены компании Alibaba и Tencent.

Примечательно, что основным мотивом создания тотального цифрового контроля над населением правительство называет заботу о безопасности граждан. Поясняя цели государственной политики, главный идеолог суверенного интернета Китая Ван Хунин сказал, что в обязанности руководства входит содействие безопасности, наведение порядка и создание надежного, стабильного и процветающего цифрового мира [Scheuer, 2018]. Отметим, что какими убедительными ни казались бы соображения о цифровом суверенитете, вынесение решений о санкционировании за рамки судебной системы и передача их на алгоритмический уровень вступают в противоречие с основными ценностями свободы личности, лежащими в основании современной демократии и международного права.

Заканчивая краткий обзор специфики взаимодействия IT-гигантов с государственными органами Китая, отметим, что характер действия Пекинского правительства в вопросе распределения власти не уникален. Принципы, на которых строится политика Китая, в той или иной степени свойственны всем автократическим системам. Они подразумевают контроль за гражданами и манипуляцию их мнением. Специфической особенностью Китайской народной республики является сильно развитый сектор цифровой индустрии, обеспечивающий эффективный контроль населения, способствующий повышению и без того высокого уровня концентрации власти в руках немногочисленной государственной элиты.

\section{Выводы}

Подытоживая проделанный в статье анализ рисков изменения властных отношений, можно прийти к заключению, что тренд концентрации власти вокруг крупнейших IT-компаний в ближайшее время будет сохраняться. Продолжению этой тенденции, очевидно, способствует сама бизнес-модель техногигантов, построенная на сборе персональных данных в целях оптимизации продукта частных компаний. Стоит ожидать, что государственные органы отчасти будут способство-

\footnotetext{
${ }^{12}$ State Council Guiding Opinions concerning Establishing and Perfecting Incentives for Promise-Keeping and Joint Punishment Systems for Trust-Breaking, and Accelerating the Construction of Social Sincerity //China Copyright and Media. 2016. October 18. URL: https://chinacopyrightandmedia.wordpress.com/2016/05/30/state-council-guiding-opinionsconcerning-establishing-and-perfecting-incentives-for-promise-keeping-and-joint-punishment-systems-for-trust-breakingand-accelerating-the-construction-of-social-sincer/ (дата обращения: 17.02.2021).

${ }^{13}$ Botsman R. Big Data Meets Big Brother as China Moves to Rate Its Citizens //Wired. URL: https://www.wired.co.uk/ article/chinese-government-social-credit-score-privacy-invasion (дата обращения: 17.02.2021).
} 
вать этому процессу, но в демократических странах такая активность будет исходить в основном от сектора безопасности. Законодательная и судебная ветви, по всей видимости, должны стать опорой противостояния процессам дальнейшей концентрации власти цифровых гигантов. Однако как в демократических, так и в авторитарных обществах главная стратегия решения вопроса баланса власти - это опора на гражданское общество. Именно оно в первую очередь заинтересовано в защите собственных прав и является бенефициаром согласованного распределения властных полномочий между общественно контролируемыми институтами власти. Для того чтобы повысить сознательную гражданскую активность, необходимо довести до общественности суть процессов, лежащих в основе экономических моделей ІТ-гигантов, раскрыть природу концентрации власти в руках новоиспеченных лидеров эпохи цифрового капитализма.

В этом процессе особая роль ложится на представителей академической среды. Возможно, наступило время разработки проекта анализа цифровых буржуазнокапиталистических отношений, направленного на раскрытие механизмов господства и подавления в эпоху информационных технологий. Опираясь на опыт, предпринятый авторами критических теорий прошлого века, академический мир должен стать в авангарде просвещения гражданского общества цифровой эпохи. Благодаря критическому мышлению общество отстояло демократические свободы в эпоху индустриального капитализма прошлого века. То же самое предстоит сделать сегодняшнему поколению по отношению к цифровому капитализму.

\section{Список литературы (References)}

Быков И.А., Халл Т. Э. Цифровое неравенство и политические предпочтения интернет-пользователей в России //Полис. Политические исследования. 2011. № 5. C. 151-163. URL: https://www.politstudies.ru/article/4473 (дата обращения: 26.02.2021).

Bykov I. A., Hall T.E. (2011) Digital Divide and the Internet-Users Political Preferences in Russia. Polis. Political Studies. No. 5. P. 151-163. URL: https://www.politstudies. ru/article/4473 (accessed: 26.02.2021). (In Russ.)

Дюркгейм Э. О разделении общественного труда. Метод социологии / пер. с фр. и послесловие Л.Б. Гофмана. М. : Наука, 1991.

Durkheim É. (1991) De la division du travail social. Moscow: Nauka. (In Russ.)

Маркузе Г. Одномерный человек: исследование идеологии развитого индустриального общества / пер. с англ. М.: АСТ, 2002.

Marcuse H. (2002) One-Dimensional Man: Studies in the Ideology of Advanced Industrial Society. Moscow: AST. (In Russ.)

Мертон Р. К. Эффект Матфея в науке, II: накопление преимуществ и символизм интеллектуальной собственности //THESIS. 1993. Вып. 3. С. 256-276.

Merton R. K. (1993) The Matthew Effect in Science, II: Cumulative Advantage and the Symbolism of Intellectual Property. THESIS. Vol. 3. P. 256-276. (In Russ.)

Мертон Р.К. Социальная теория и социальная структура / пер. с англ. Е.Н. Егоровой. М.: АСТ, Хранитель, 2006. 
Merton R. K. (2006) Social Theory and Social Structure. Moscow: AST; Khranitel. (In Russ.)

Талер Р. Санстейн К. (2017). Nudge. Архитектура выбора. Как улучшить наши решения о здоровье, благосостоянии и счастье. М.: Манн, Иванов и Фербер.

Thaler R., Sunstein C. (2017) Nudge: Improving Decisions About Health, Wealth, and Happiness. Moscow: Mann, Ivanov and Ferber. (In Russ.)

Хабермас Ю. Структурное изменение публичной сферы: Исследования относительно категории буржуазного общества. М.: Весь Мир, 2016.

Habermas J. (2016) Strukturwandel der Öffentlichkeit: Untersuchungen zu einer Kategorie der bürgerlichen Gesellschaft. Moscow: Ves Mir. (In Russ.)

Хоркхаймер М., Адорно Т., Диалектика Просвещения. Философские фрагменты. М.; СПб.: Медиум : Ювента, 1997.

Horkheimer M., Adorno T. (1997) Dialektik der Aufklaerung. Philosophische Fragmente. Moscow, St. Petersburg: Medium; Yuventa.

Черняк Л. Аналитика двойного назначения // Открытые системы-СУБД. 2013. № 10. URL: https://www.osp.ru/os/2013/10/13039073 (дата обращения: 26.02.2021).

Chernyak L. (2013) Dual-Use Analytics. Otkrytye sistemy - SUBD. No. 10. URL: https:/ / www.osp.ru/os/2013/10/13039073 (accessed: 26.02.2021). (In Russ.)

Dolata U. (2019) Internet Plattformen Regulierung. Koordination von Märkten und Kuratierung von Sozialität im Internet. Berliner Journal für Soziologie. Vol. 129. P. 179206. https://doi.org/10.1007/s11609-020-00403-9.

Gillespie T. (2010) The Politics of "Platforms". New Media \& Society. Vol. 12. No. 3. P. 347-364.

Habermas J. (1988) Theorie des kommunikativen Handelns. In 2 Bände. Band 2. Zur Kritik der funktionalistischen Vernunft. Frankfurt am Main: Suhrkamp.

Jeffrey R. (1974) A Theory of Interdependent Demand for a Communications Service. Bell Journal of Economics and Management Science. Vol. 5. No. 1. P. 16-37.

Langley P., Leyshon A. (2016) Platform Capitalism: The Intermediation and Capitalization of Digital Economic Circulation. Finance and Society. Vol. 2. No. 1. URL: https://www. google.com/url?sa=t\&rct=j\&q=\&esrc=s\&source=web\&cd=\&ved=2ahUKEwjHOZ7Sk oPvAhVdAhAlHc1rBygQFjAAegQIARAD\&url=http\%3A\%2F\%2Ffinanceandsociety.ed.ac. uk\%2Fojs-images\%2Ffinanceandsociety\%2FFS_EarlyView_LangleyLeyshon.pdf\&usg= AOvVaw2jLzeFjuJtaZgILCAV7tPA (accessed: 23.02.2021).

Lobel O. (2016) The Law of the Platform. San Diego Legal Studies Paper. No. 16212. Minnesota Law Review. URL: https://papers.ssrn.com/sol3/Delivery.cfm/ SSRN_ID2742380_code514132.pdf?abstractid=2742380\& mirid=1 (accessed: 23.02.2021).

Moore M., Tambini D. (2018) Digital Dominance. The Power of Google, Amazon, Facebook, and Apple. New York, NY: Oxford University Press. 
Scheuer S. (2018) Der Masterplan. Chinas Weg zur Hightech-Weltherrschaft. Verlag Herder GmbH, Freiburg im Breisgau.

Schwartz P. M. (1989) The Computer in German and American Constitutional Law: Towards an American Right of Informational Self-Determination. American Journal of Comparative Law. Vol. 37. No. 4. P. 675-701. https://doi.org/10.2307/840221.

Srnicek N. (2016) Platform Capitalism (Theory Redux). Cambridge: Polity.

Staab Ph. (2019) Digitaler Kapitalismus Markt und Herrschaft in der Ökonomie der Unknappheit. Berlin: Suhrkamp Verlag.

Zuboff Sh. (2018) Das Zeitalter des Überwachungs-Kapitalismus. Frankfurt: Campus. Zysman J, Kenney M. (2016) The Next Phase in the Digital Revolution Platforms, Abundant Computing, Growth and Employment. BRIE Working Paper. 